\title{
РАСПРОСТРАНЕННОСТЬ ЗУБОЧЕЛЮСТНЫХ АНОМАЛИЙ И ДЕФОРМАЦИЙ У ДЕТЕЙ
}

\section{PREVALENCE OF DENTAL ANOMALIES AND DEFORMITIES IN CHILDREN}

A. Bril

T. Makarchuk

A. Ivanov

D. Cherepanova

V. Petrova

T. Snytko

Summary. The purpose of the study is to justify the need for early orthodontic treatment of children and adolescents.

Material and methods. In order to study the prevalence of dental anomalies and deformities in children of Krasnoyarsk, 1,479 children with compensated dental caries were examined. In order to study the frequency of HRT in children with multiple caries, we examined 981 children.

Results. In the course of the study, it was revealed that during the period of formed temporary bite, the prevalence of ZCHAD in conditionally healthy children and adolescents in Krasnoyarsk was $31.83 \pm 2.44 \%$. In the initial period of replacement bite, there was a higher prevalence of ESRD $40.45 \pm 2.66 \%$. In the period of permanent occlusion, a decrease in the prevalence of PTSD in conditionally healthy children was detected $34.55 \pm 2.37 \%$. The authors recommend that orthodontists conduct mandatory preventive examinations of all children after the age of five in order to conduct early orthodontic treatment.

Keywords: children, adolescents, prevalence of dentofacial anomalies and deformations, structure of dentofacial anomalies and deformations, multiple caries, periods of development of the dentofacial system.
Бриль Елена Александровна

Д.м.н., дочент, Красноярский государственный медицинский университет имени профессора

В. Ф. Войно-Ясенецкого e.a.b.27@mail.ru

Макарчук Тихон Максимович

Красноярский государственный медицинский университет имени профессора В. Ф. Войно-Ясенецкого

mmy68@bk.ru

Иванов Алексей Николаевич

Красноярский государственный медицинский университет имени профессора В. Ф. Войно-Ясенецкого boxerlexa@mail.ru

Черепанова Дарья Сергеевна

Красноярский государственный медицинский университет имени профессора В. Ф. Войно-Ясенецкого

DaryaCher97@yandex.ru

Петрова Валерия Вячеславовна

Красноярский государственный медицинский университет имени профессора В. Ф. Войно-Ясенецкого

Pvv_eriya@mail.ru

Снытко Татьяна Владимировна

Красноярский государственный медицинский университет имени профессора В. Ф. Войно-Ясенецкого snytkotatyana19@gmail.com

Аннотация. Цель исследования — обосновать необходимость проведения раннего ортодонтического лечения детей и подростков.

Материал и методы. С целью изучения распространенности зубочелюстных аномалий и деформаций (ЗЧАД) у детей г. Красноярска было обследовано 1479 детей, имеющих компенсированную форму кариеса зубов. С целью изучения частоты ЗЧАД у детей с множественным кариесом мы обследовали 981 ребенка.

Результаты. В процессе исследования выявлено, что в период сформированного временного прикуса, распространенность ЗЧАДу условно здоровых детей и подростков г. Красноярска составляла $31,83 \pm 2,44 \%$. В начальном периоде сменного прикуса отмечена более высокая распространенность

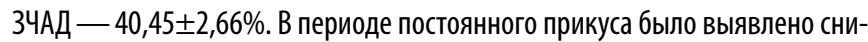
жение распространенности ЗЧАДуусловно здоровыхдетей $-34,55 \pm 2,37 \%$. Авторы рекомендуют ортодонтам проводить обязательные профилактические осмотры всех детей после пяти лет с целью проведения раннего ортодонтического лечения.

Ключевые слова: дети, подростки, распространенность зубочелюстных аномалии и деформации, структура зубочелюстных аномалии и деформации, множественный кариес, периоды развития зубочелюстной системы. 


\section{Ввемение}

3 убочелюстные аномалии и деформации имеют высокую распространенность у детей и подростков $[1,2,5,7]$. Структура ЗЧАД во многом зависит от этиологического фактора, вызвавшего данное нарушение зубочелюстной системы $[3,4,6]$. Следует отметить, что ранняя диагностика зубочелюстных аномалий у детей имеет первостепенное значение в связи с развитием персонализированного подхода и возможностью ортодонтической коррекции ЗЧАД у детей и подростков на всех этапах формирования прикуса.

\section{Материалы и методы исслеАования}

С целью изучения распространенности и структуры зубочелюстных аномалий и деформаций (ЗЧАД) мы обследовали 1479 соматически здоровых детей (детей 1-2 группы здоровья, имеющих компенсированную форму кариеса зубов - интенсивность кариеса по индексу КПУ от 0 до 3), проживающих с момента рождения в г. Красноярска. С целью изучения частоты и структуры ЗчАД у детей с множественным кариесом (детей, имеющих интенсивность кариеса по индексу КПУ от 4 и более) мы обследовали 981 ребенка. Все дети находились на диспансерном учете у врача педиатра по поводу хронических соматических заболеваний. Для исключения влияния антропогенных факторов на структуру ЗЧАД, в данную группу вошли дети и подростки в возрасте от 3 до 16 лет, проживающие с момента рождения в г. Красноярске.

\section{Результаты исслеАования} и их обсужАение

Наше исследование показало, что в период сформированного временного прикуса, показатель рас-

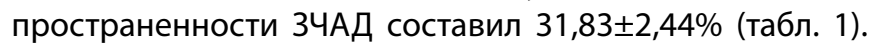
В начальном периоде сменного прикуса значение распространенности было достоверно выше и соста-

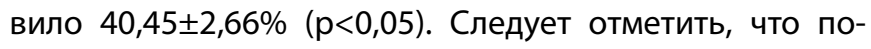
казатель распространенности оставался примерно на том же уровне и в конечном периоде сменного прикуса $-43,65 \pm 2,50 \%$. В периоде постоянного прикуса обнаружено снижение показателя распространенности ЗЧАД - 34,55 $22,37 \%$ ( $p<0,01)$. Необходимо отметить, что при обследовании 1479 соматически здоровых детей, только у 559 человек были выявлены ЗЧАД. Таким образом, показатель распространенности ЗЧАД у здоровых детей г. Красноярска в среднем не значительно отличался от данных по другим регионам и составлял $37,80 \pm 1,46 \%$.

Изучение структуры ЗЧАД у здоровых детей выявило преобладание показателя распространенности

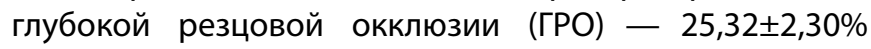

(табл. 2). Реже диагностировали аномалии зубных рядов (АЗР) - 23,35 11,42. Дистальная окклюзия (ДО) встречалась в $19,27 \pm 1,75 \%$ случаев ( $<<0,01)$. У здоровых детей показатель распространенности мезиальной окклюзии

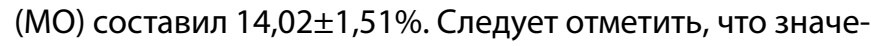
ния распространенности перекрестной окклюзии (ПО) и вертикальной резцовой дизокклюзии (ВРД) составляли соответственно 9,25 $\pm 1,34 \%$ и 8,79 $\pm 1,21 \%(p<0,001)$. Отмечено, что глубокая резцовая окклюзия (ГРО) достоверно чаще встречалась в двух периодах развития зубочелюстной системы. В периоде сформированного временного прикуса показатель распространенности ГРО

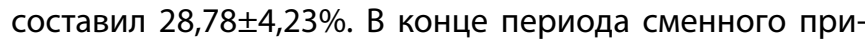

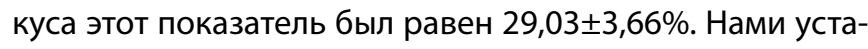
новлено, что АЗР рядов достоверно чаще встречались в конечном периоде сменного прикуса - 29,05 $\pm 3,31 \%$ $(p<0,001)$. Необходимо отметить, что этот показатель в 2,7 раза превышает значение показателя распространенности АЗР, выявленную в периоде сформированного временного прикуса.

Анализ распространенности дО у здоровых детей показал, что своего максимального значения показатель распространенности достигал в периоде сформированного временного прикуса $-22,17 \pm 3,17 \%(p<0,05)$. Установлено, что ДО встречается в 1,5 раза реже в начальном периоде сменного прикуса. Следует отметить, что MO у здоровых детей во всех изучаемых периодах развития зубочелюстной системы встречалась примерно с одинаковой частотой. Показатели распространенности МО находились в пределах 13,67\% - 14,55\% и различия их были недостоверны. Исследование показало, что показатель распространенности ПО максимального значения в начальном периоде сменного при-

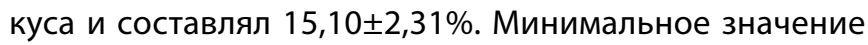
распространенности ПО было выявлено в конечном

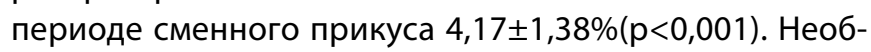
ходимо отметить, что значение распространенности

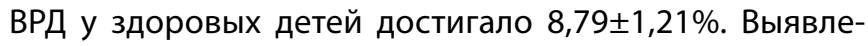
но, что показатель распространенности ВРД наибольшего значения достигал в периоде сформированного временного прикуса - 16,78 $3,42 \%$, а минимального в конечном периоде сменного прикуса $-3,78 \pm 2,25 \%$ $(\mathrm{p}<0,01)$.

С целью изучения частоты и структуры ЗЧАД у детей с множественным кариесом мы обследовали 981 ребенка. Проведенное обследование показало, что показатель распространенности ЗЧАД у детей с множественным кариесом зубов составил 76,15\% (табл. 3). Следует уточнить, что минимального значения этот показатель достигал в периоде сформированного временного прикуса $-52,75 \pm 3,77 \%$ ( $p<0,001)$. Максимальное значение показателя распространенности было отмечено в пери-

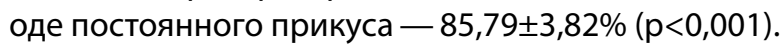


Таблица 1. Распространенность ЗЧАД у соматически здоровых детей

\begin{tabular}{|c|c|c|}
\hline \multirow{2}{*}{ Изучаемые периоды развития зубочелюстной системы } & \multicolumn{2}{|c|}{ Количество детей с ЗЧАД } \\
\hline & абс. число & $(\%),(M \pm m)$ \\
\hline $\begin{array}{l}\text { 1. Период сформированного временного прикуса (3-5лет). } \\
\mathrm{n}=311\end{array}$ & 99 & $31,83 \pm 2,44$ \\
\hline $\begin{array}{l}\text { 2. Начальный период сменного прикуса (6-9лет). } \\
\text { n=314 }\end{array}$ & 127 & $\begin{array}{l}40,45 \pm 2,66 \\
\mathrm{p}_{1,2}<0,05\end{array}$ \\
\hline $\begin{array}{l}\text { 3. Конечный период сменного прикуса (10-12лет). } \\
\mathrm{n}=417\end{array}$ & 182 & $\begin{array}{l}43,65 \pm 2,50 \\
\mathrm{p}_{1,3}<0,001 \\
\end{array}$ \\
\hline $\begin{array}{l}\text { 4. Период постоянного прикуса (13-16лет). } \\
\mathrm{n}=437\end{array}$ & 151 & $\begin{array}{l}34,55 \pm 2,37 \\
P_{3,4}<0,01\end{array}$ \\
\hline $\begin{array}{l}\text { 5. Bсего: } \\
n=1479\end{array}$ & 559 & $37,80 \pm 1,46$ \\
\hline
\end{tabular}

Примечание: $\mathrm{n}$ - количество обследованных детей; $\mathrm{p}$ - достоверность различий определена по отношению к показателям соответствующей группы исследования $(1,2,3,4)$.

Таблица 2. Частота и структура ЗЧАД у соматически здоровых детей

\begin{tabular}{|c|c|c|c|c|c|c|}
\hline \multirow{2}{*}{$\begin{array}{l}\text { Изучаемые периоды развития } \\
\text { зубочелюстной системы }\end{array}$} & \multicolumn{6}{|c|}{ 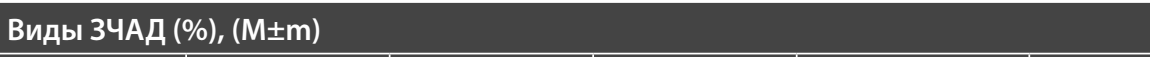 } \\
\hline & ГРО & A3P & до & MO & по & ВРД \\
\hline $\begin{array}{l}\text { 1. Период сформированного } \\
\text { временного прикуса } \\
\text { (3-5лет). } \\
n=311\end{array}$ & $\begin{array}{l}28,78 \\
\pm 4,23\end{array}$ & $\begin{array}{l}10,93 \\
\pm 4,27\end{array}$ & $\begin{array}{l}22,17 \\
\pm 2,17\end{array}$ & $\begin{array}{l}14,55 \\
\pm 3,27\end{array}$ & $\begin{array}{l}6,79 \\
\pm 2,56\end{array}$ & $\begin{array}{l}16,78 \\
\pm 3,42\end{array}$ \\
\hline $\begin{array}{l}\text { 2. Начальный период сменного } \\
\text { прикуса } \\
\text { (6-9лет). } \\
\text { n=314 }\end{array}$ & $\begin{array}{l}21,84 \\
\pm 3,22\end{array}$ & $\begin{array}{l}26,96 \\
\pm 3,47 \\
p_{1,2}<0,01\end{array}$ & $\begin{array}{l}14,87 \\
\pm 2,10 \\
\mathrm{p}_{1,2}<0,05\end{array}$ & $\begin{array}{l}14,02 \\
\pm 2,61\end{array}$ & $\begin{array}{l}15,10 \\
\pm 2,31 \\
p_{1,2}<0,05\end{array}$ & $\begin{array}{l}7,21 \\
\pm 2,18 \\
p_{1,2}<0,05\end{array}$ \\
\hline $\begin{array}{l}\text { 3. Конечный период сменного } \\
\text { прикуса } \\
\text { (10-12лет). } \\
\text { n=417 }\end{array}$ & $\begin{array}{l}29,03 \\
\pm 3,66\end{array}$ & $\begin{array}{l}29,05 \\
\pm 3,31 \\
p_{1,3}<0,01\end{array}$ & $\begin{array}{l}20,15 \\
\pm 2,13\end{array}$ & $\begin{array}{l}13,82 \\
\pm 2,69\end{array}$ & $\begin{array}{l}4,17 \\
\pm 1,38 \\
p_{2,3}<0,001\end{array}$ & $\begin{array}{l}3,78 \\
\pm 2,25 \\
p_{1,3}<0,01\end{array}$ \\
\hline $\begin{array}{l}\text { 4. Период постоянного прикуса } \\
\text { (13-16лет). } \\
n=437\end{array}$ & $\begin{array}{l}22,03 \\
\pm 3,25\end{array}$ & $\begin{array}{l}26,08 \\
\pm 3,74 \\
\mathrm{p}_{1,4}<0,01\end{array}$ & $\begin{array}{l}19,97 \\
\pm 3,07\end{array}$ & $\begin{array}{l}13,67 \\
\pm 2,13\end{array}$ & $\begin{array}{l}10,94 \\
\pm 2,44 \\
p_{3,4}<0,05 \\
\end{array}$ & $\begin{array}{l}7,31 \\
\pm 2,18 \\
\mathrm{p}_{1,4}<0,05\end{array}$ \\
\hline $\begin{array}{l}\text { 5. Всего: } \\
n=1479\end{array}$ & $\begin{array}{l}25,32 \\
\pm 2,30\end{array}$ & $\begin{array}{l}23,35 \\
\pm 1,42\end{array}$ & $\begin{array}{l}19,27 \\
\pm 1,75\end{array}$ & $\begin{array}{l}14,02 \\
\pm 1,51\end{array}$ & $\begin{array}{l}9,25 \\
\pm 1,34\end{array}$ & $\begin{array}{l}8,79 \\
\pm 1,21\end{array}$ \\
\hline
\end{tabular}

Примечание: $\mathrm{n}$ - количество обследованных детей; $\mathrm{p}$ - достоверность различий определена по отношению к показателям соответствующей группы исследования $(1,2,3,4)$.

В начальном периоде сменного прикуса, показатель распространенности зубочелюстных аномалий и деформаций у детей с множественным кариесом зубов увеличивался в 1,5 раза, по сравнению с показателем распространенности, выявленным у детей в периоде сформированного временного прикуса $(p<0,001)$.

Согласно полученным данным (табл. 4), показатель распространенности ЗЧАД у детей с множественным кариесом зубов на 38,35\% был выше по сравнению с показателем распространенности в группе здоровых детей $(p<0,001)$. Наибольшие значения данного показателя мы отметили в двух периодах. Так, в начальном периоде сменного прикуса, показатель распространенности ЗЧАД у детей с множественным кариесом зубов был в 2 раза выше по сравнению с показателем распространенности, выявленном в группе здоровых детей ( $<<0,001)$. А в периоде постоянного прикуса показатель распространенности увеличился в 2,5 раза ( $<<0,001)$. С возрастом (от 3-х до 16-и лет) распространенность ЗЧАД у детей с множественным кариесом зубов увеличивалась на 33,04\% и достоверно отличалась от показателя в группе здоровых детей $(p<0,001)$. У детей с множественным кариесом зубов чаще всего выявляли ДО - 37,27 $\pm 2,21 \%$ (табл. 5). Второе место по рас-

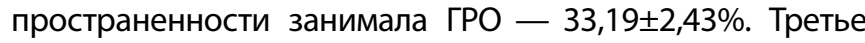

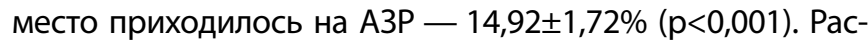


Таблица 3. Распространенность ЗЧАД у детей с множественным кариесом зубов

\begin{tabular}{|c|c|c|}
\hline \multirow{2}{*}{ Изучаемые периоды развития зубочелюстной системы } & \multicolumn{2}{|c|}{ Количество детей с ЗЧАД } \\
\hline & абс. число & $(\%),(M \pm m)$ \\
\hline $\begin{array}{l}\text { 1. Период сформированного временного прикуса } \\
\text { (3-5лет). } \\
n=182\end{array}$ & 96 & $52,75 \pm 3,77$ \\
\hline $\begin{array}{l}\text { 2. Начальный период сменного прикуса } \\
\text { (6-9лет). } \\
\text { n=454 }\end{array}$ & 367 & $\begin{array}{l}80,84 \pm 2,63 \\
p_{1,2}<0,001\end{array}$ \\
\hline $\begin{array}{l}\text { 3. Конечный период сменного прикуса } \\
\text { (10-12лет). } \\
\mathrm{n}=162\end{array}$ & 127 & $\begin{array}{l}78,40 \pm 4,36 \\
p 1,3<0,001\end{array}$ \\
\hline $\begin{array}{l}\text { 4. Период постоянного прикуса } \\
\text { (13-16лет). } \\
n=183\end{array}$ & 157 & $\begin{array}{l}85,79 \pm 3,82 \\
p_{1,4}<0,001\end{array}$ \\
\hline $\begin{array}{l}\text { 5. Всего: } \\
\mathrm{n}=981\end{array}$ & 747 & $76,15 \pm 2,73$ \\
\hline
\end{tabular}

Примечание: $\mathrm{n}$ - количество обследованных детей с ИДС; $\mathrm{p}$ - достоверность различий определена по отношению к показателям соответствующей группы исследования $(1,2,3,4)$.

Таблица 4. Сравнительная характеристика распространенности ЗЧАД у детей с различной степенью активности кариеса зубов

\begin{tabular}{|c|c|c|c|c|c|}
\hline \multirow[t]{2}{*}{ Группы исследования } & \multicolumn{5}{|c|}{ 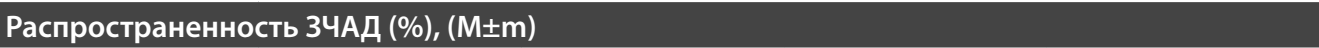 } \\
\hline & 3-5 лет & 6-9 лет & 10-12 лет & 13-16 лет & $\begin{array}{l}\text { Средние значения } \\
\text { для группы }\end{array}$ \\
\hline $\begin{array}{l}\text { Группа здоровых детей, } \\
\text { имеющих компенсированную } \\
\text { форму кариеса зубов } \\
\text { n=559 }\end{array}$ & $\begin{array}{l}n=99 \\
31,83 \pm 2,44\end{array}$ & $\begin{array}{l}n=127 \\
40,45 \pm 2,66\end{array}$ & $\begin{array}{l}n=182 \\
43,65 \pm 2,50\end{array}$ & $\begin{array}{l}n=151 \\
34,55 \pm 2,37\end{array}$ & $37,80 \pm 1,46$ \\
\hline $\begin{array}{l}\text { Группа детей } \\
\text { с множественным кариесом } \\
\text { зубов } \\
\text { n=747 }\end{array}$ & $\begin{array}{l}n=96 \\
52,75 \pm 3,77 \\
p<0,001\end{array}$ & $\begin{array}{l}n=367 \\
80,84 \pm 2,63 \\
p<0,001\end{array}$ & $\begin{array}{l}n=127 \\
78,40 \pm 4,36 \\
p<0,001\end{array}$ & $\begin{array}{l}n=157 \\
85,79 \pm 3,82 \\
p<0,001\end{array}$ & $\begin{array}{l}76,15 \pm 2,73 \\
p<0,001\end{array}$ \\
\hline
\end{tabular}

Примечание: $\mathrm{n}$ - количество детей с ЗЧАД; $\mathrm{p}$ - достоверность различий определена по отношению к показателям группы здоровых детей.

Таблица 5. Частота и структура ЗЧАД у детей с множественным кариесом зубов

\begin{tabular}{|c|c|c|c|c|c|c|}
\hline \multirow{2}{*}{$\begin{array}{l}\text { Изучаемые периоды } \\
\text { развития зубочелюстной } \\
\text { системы }\end{array}$} & \multicolumn{6}{|c|}{ Виды ЗЧАД (\%), (M $\pm m)$} \\
\hline & ГРО & A3P & до & MO & По & ВРД \\
\hline $\begin{array}{l}\text { 1. Период } \\
\text { сформированного } \\
\text { временного прикуса } \\
\text { (3-5лет), } n=182\end{array}$ & $30,45 \pm 5,17$ & $5,65 \pm 1,72$ & $47,03 \pm 5,81$ & $2,25 \pm 1,34$ & $2,60 \pm 1,47$ & $12,02 \pm 2,44$ \\
\hline $\begin{array}{l}\text { 2. Начальный период } \\
\text { сменного прикуса } \\
\text { (6-9лет), n=454 }\end{array}$ & $29,82 \pm 3,36$ & $\begin{array}{l}14,31 \pm 1,87 \\
p_{1,2}<0,001\end{array}$ & $36,94 \pm 3,45$ & $1,53 \pm 0,28$ & $6,93 \pm 2,43$ & $10,47 \pm 2,91$ \\
\hline $\begin{array}{l}\text { 3. Конечный период } \\
\text { сменного прикуса } \\
\text { (10-12лет), } n=162\end{array}$ & $36,75 \pm 4,23$ & $\begin{array}{l}22,69 \pm 4,31 \\
p_{1,3}<0,001\end{array}$ & $\begin{array}{l}29,17 \pm 4,68 \\
p_{1,3}<0,05\end{array}$ & $1,65 \pm 0,15$ & $2,36 \pm 1,26$ & $7,38 \pm 2,37$ \\
\hline $\begin{array}{l}\text { 4. Период постоянного } \\
\text { прикуса (13-16лет), } n=183\end{array}$ & $35,72 \pm 5,19$ & $\begin{array}{l}17,02 \pm 2,68 \\
\mathrm{p}_{1,4}<0,001\end{array}$ & $35,92 \pm 4,73$ & $2,66 \pm 1,17$ & $2,66 \pm 1,17$ & $6,02 \pm 2,10$ \\
\hline 5. Всего: $n=981$ & $33,19 \pm 2,43$ & $14,92 \pm 1,72$ & $37,27 \pm 2,21$ & $2,02 \pm 0,74$ & $3,64 \pm 1,22$ & $8,96 \pm 0,65$ \\
\hline
\end{tabular}

Примечание: $\mathrm{n}$ - количество обследованных детей; $\mathrm{p}$ - достоверность различий определена по отношению к показателям соответствующей группы исследования $(1,2,3,4)$. 


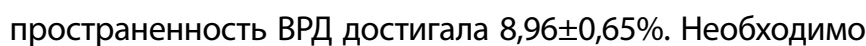
отметить, что распространенность ПО у детей с множе-

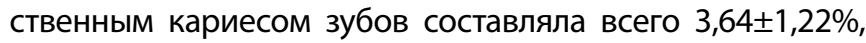
а мезиальной окклюзии -2,02\%.

\section{Зак^ючение}

В процессе исследования выявлено, что в период сформированного временного прикуса распространенность ЗЧАД у соматически здоровых детей г. Красноярска составляла $31,83 \pm 2,44 \%$. В начальном периоде сменного прикуса отмечена более высокая распространенность ЗЧАД - 40,45 $22,66 \%(p<0,05)$. Следует отметить, что показатель распространенности оставался примерно на том же уровне и в конечном периоде сменного прикуса - 43,65士2,50\%. В периоде постоянного прикуса было выявлено снижение распространенности ЗЧАД у соматически здоровых детей $-34,55 \pm 2,37 \%(p<0,01)$. Установлено, что распространенность ЗЧАД у детей с множественным кариесом составляла 76,15\%. Следует отметить, что с возрастом распространенность ЗЧАД у детей с множественным кариесом зубов увеличилась на 33,04\% и достоверно отличалась от показателей группы соматически здоровых детей $(p<0,001)$ Учитывая данные нашего исследования, мы рекомендуем врачам ортодонтам проводить диспансеризацию здоровых детей с целью раннего выявления факторов риска в развитии ЗЧАД. Формирование диспансерных групп детей на приеме ортодонта позволит персонализировано проводить раннее аппаратурное лечение.

\section{ЛИТЕРАТУРА}

1. Алимский А. В. Возрастная динамика роста распространенности и изменения структуры аномалий среди дошкольников и школьников //Стоматология.— 2010.—№ 5.— - . 67-71.

2. Вакушина Е.А., Брагин Е. А. Распространенность аномалий окклюзии среди подростков и взрослых г. Ставрополя //0ртодонтия. — 2003.— № 2. — С. 2932.

3. Даминов Т.О., Якубов Р. К., Мавлянов И. Р., Ахмедова Д. И., Пигарев В.Я. Роль общих факторов в патогенезе развития деформаций деформаций зубочелюстной системы у детей. - Стоматология. - 2002.— № 4. - С. 57-60.

4. Дистель В.А., Сунцов В. Г., Вагнер В.Д. Зубочелюстные аномалии и деформации. - Омск: Изд-во НГМА, 2001. — 100 с.

5. Манин А.И., Ретинская М. В., Тачиева В. П., Мальсагов 0. М., Мастерова И. В. Распространенность аномалий зубов у жителей различных регионов России // Ортодонтия. - 2003.- № 4.- С. 9-12.

6. Проффит У. Р. Современная ортодонтия (под ред чл.- корр. РАМН, проф. Персина Л. С.).— М., «МЕДпресс — информ, 2019. — 712 с.

7. Хорошилкина Ф.Я. Ортодонтия. М.: Мед. информ. агентство, 2006. - 544 с.

๑ Бриль Елена Александровна ( e.a.b.27@mail.ru ), Макарчук Тихон Максимович ( mmy68@bk.ru ), Иванов Алексей Николаевич ( boxerlexa@mail.ru ), Черепанова Дарья Сергеевна ( DaryaCher97@yandex.ru ), Петрова Валерия Вячеславовна ( Pvv_eriya@mail.ru ),Снытко Татьяна Владимировна ( snytkotatyana19@gmail.com ). Журнал «Современная наука: актуальные проблемы теории и практики» 